\title{
Cross-Aldol Reaction of Isatin with Acetone Catalyzed by Leucinol: A Mechanistic Investigation
}

\author{
Mikhail A. Kabeshov, ${ }^{a, b}$ Ondřej Kysilka, ${ }^{c}$ Lubomír Rulíšek, ${ }^{d}$ Yury V. Suleimanov, ${ }^{e}$ \\ Marco Bella, ${ }^{\dagger}$ Andrei V. Malkov, ${ }^{* a}$ and Pavel Kočovský ${ }^{* d, g}$
}

\author{
Dedicated to Professor Gilbert Stork on the occasion of his $94^{\text {th }}$ birthday and in \\ appreciation of his pioneering work in the area of enamines.
}

\begin{abstract}
Comprehensive mechanistic studies of the enantioselective aldol reaction between isatin (1a) and acetone, catalyzed by L-leucinol (3a), unraveled that isatine, apart from being a substrate, also plays an active catalytic role. Conversion of the intermediate oxazolidine $\mathbf{4}$ into the reactive syn-enamine $\mathbf{6}$, catalyzed by isatin, was identified as the rate determining step by both the calculations $\left(\Delta G^{\neq}=26.1 \mathrm{kcal} \mathrm{mol}^{-1}\right.$ for the analogous L-alaninol, $\left.3 \mathbf{b}\right)$ and the kinetic isotope effect $\left(k_{H} / k_{D}=2.7\right.$ observed for the reaction using $d_{6}$-acetone). The subsequent reaction of the syn-enamine 6 with isatin produces $(S)-\mathbf{2 a}$ (calculated $\Delta G^{\neq}=11.6 \mathrm{kcal} \mathrm{mol}^{-1}$ ). The calculations suggest that the overall stereochemistry is controlled by two key events: (1) the isatin-catalyzed formation of the syn-enamine $\mathbf{6}$, which is thermodynamically favored over its antirotamer $\mathbf{7}$ by $2.3 \mathrm{kcal} \mathrm{mol}^{-1}$; and (2) the high preference of the syn-enamine $\mathbf{6}$ to produce $(S)-\mathbf{2 a}$ on reaction with isatin (1a) rather than its enantiomer $\left(\Delta \Delta G^{\neq}=2.6 \mathrm{kcal} \mathrm{mol}^{-1}\right)$.
\end{abstract}

\section{Introduction}

Proline and related secondary amines have enjoyed a widespread use as chiral organocatalysts in aldol and other reactions, which proceed via enamine intermediates. ${ }^{[1-5]}$ By contrast, primary amines have only been utilized occasionally, ${ }^{[1,6]}$ presumably owing to their tendency to form stable imines rather than enamines. Furthermore, in contrast to the successful reactions between an aldehyde and a ketone, the catalytic ketone-ketone cross-aldol reactions are rare. ${ }^{[1,2,7]}$ Part of the problem here, aside from the competing self- and cross-

[a] Prof. Dr. A. V. Malkov, Dr. M. A. Kabeshov

Department of Chemistry, Loughborough University, Loughborough, Leics LE11 3TU (UK)

E-mail: a.malkov@lboro.ac.uk

[b] Dr. M. A. Kabeshov

Department of Chemistry, University of Cambridge, Lensfield Road, Cambridge CB2 1EW (UK)

E-mail: mk787@cam.ac.uk

[c] Dr. O. Kysilka

FARMAK, Klášterní Hradisko, 77900 Olomouc (Czech Republic)

[d] Dr. L. Rulíšek, Prof. Dr. P. Kočovský

Institute of Organic Chemistry and Biochemistry, Academy of

Sciences of the Czech Republic, Flemingovo nám. 2, 16610 Prague 6 (Czech Republic)

[e] Dr. Y. V. Suleimanov

Computation-based Science and Technology Research Center

Cyprus Institute, 20 Kavafi Str., Nicosia 2121, Cyprus \& Department of Chemical Engineering, Massachusetts Institute of Technology, Cambridge, Massachusetts 02139 (USA)

[f] Dr. M. Bella

Department of Chemistry, "Sapienza" University of Rome, Piazzale Aldo Moro 5, 00185 Rome (Italy)

[g] Prof. Dr. P. Kočovský

Department of Organic Chemistry, Arrhenius Laboratory, Stockholm University, SE 10691 Stockholm (Sweden) \& Department of Organic Chemistry, Charles University, Hlavova 8, 12843 Prague 2 (Czech Republic)

E-mail: pavel@organ.su.se

Supporting information for this article is given via a link at the end of the document. coupling, is that the corresponding aldol products tend to be less stable than their precursors, so that the equilibrium is often shifted toward the starting materials. ${ }^{[8]}$ Hence, to attain good conversions and high selectivity, one of the partners has to be more electrophilic and preferably non-enolizable, whereas the other counterpart should readily produce enols and consequently enamines, all in a catalytic manifold.

Isatin (1a), a non-enolizable activated ketone, has been the focus of numerous catalytic studies. ${ }^{[9,10]}$ In our preliminary paper ${ }^{[9]}$ we have reported on an asymmetric synthesis of both enantiomers of convolutamydine $A(\mathbf{2 b})^{[11]}$ from 4,6dibromoisatin 1b and acetone (a symmetrical, enolizable ketone). Rather surprisingly, leucinol (3a) and valinol, i.e., vicinal amino alcohols with a primary amino group at the chiral center, were identified as the most efficient catalysts (Scheme 1), by far superior to proline and its congeners. ${ }^{[9]}$

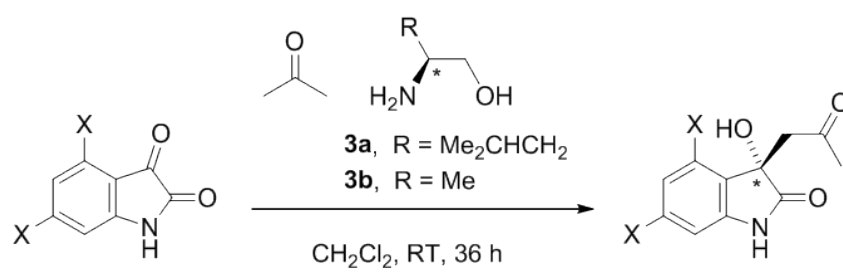
1a, $X=\mathrm{H}$
(S)-2a, $\mathrm{X}=\mathrm{H}$
1b, $X=\mathrm{Br}$
(S)-2b, $\mathbf{X}=\mathrm{Br}$

Scheme 1. Aldol reaction catalyzed by amino alcohols

Computational studies, carried by Houk, Barbas, List, and Armstrong and Rzepa ${ }^{[3 a, 3 b, 12]}$ for the proline-based catalytic system, recently unveiled the origins of the enantio- and diastereoselectivity in the aldehyde-aldehyde aldol reaction catalyzed by primary amino acids. ${ }^{[12]}$ However, the mechanistic picture of a synthetically more challenging ketone-ketone aldol reaction and in particular, the surprisingly high efficiency of primary amino alcohols as catalysts, remain unclear. ${ }^{[13]}$ Herein 
we provide a mechanistic insight into this catalytic process based on quantum chemistry calculations and kinetic studies.

\section{Results and Discussion}

The aldol reaction of isatin (1a) with acetone (30 equivs), carried out in $\mathrm{CH}_{2} \mathrm{Cl}_{2}$ (with $0.1 \%$ of water), ${ }^{[14]}$ proceeded readily at room temperature $\left(\sim 18{ }^{\circ} \mathrm{C}\right)$ over $36 \mathrm{~h}$ in the presence of 20 mol\% of L-leucinol (3a), giving rise to the aldol product (S)-(-)-2a (87\% isolated yield, $94 \%$ ee).$^{[9,15]}$

The latter reaction was found to be first-order in $1 \mathrm{a}$ and the key importance of the $\mathrm{NH}_{2}$ and $\mathrm{OH}$ groups has been demonstrated. ${ }^{[9]}$ The reaction can also be catalyzed by $\mathrm{BuNH}_{2}$ or $\mathrm{Et}_{2} \mathrm{NH}$, whereas $\mathrm{Et}_{3} \mathrm{~N}$ was found to be inert, suggesting an enamine intermediate. Furthermore, $\mathrm{N}$-methylleucinol failed to catalyze the reaction at an appreciable rate, demonstrating the key importance of the primary amino group. On the other hand, the methyl ether of leucinol and O-trimethylsilylleucinol turned out to catalyze the reaction but more slowly and far less selectively than leucinol (both reached $\sim 50 \%$ conversion over 36 $\mathrm{h}$ at RT, with $50 \%$ ee). The observed linear correlation between the enantiopurity of leucinol and that of the aldol product $2 \mathrm{a}$ (after full conversion) shows that only one molecule of the catalyst is likely to be involved in the stereo-discriminating step. ${ }^{[9]}$ Monitoring a mixture of acetone and leucinol in $\mathrm{CDCl}_{3}$ by NMR spectroscopy ${ }^{[\mathbf{b}}$ revealed a gradual conversion of leucinol into oxazolidine 4 (Scheme 2), reaching completion within $2 \mathrm{~h}$ at $37^{\circ} \mathrm{C}$. No other species could be detected but the existence of intermediates 5-7 in the equilibrium can be envisioned (in concentrations below the NMR detection threshold). Interestingly, isatin 1a (added to a mixture of leucinol and acetone in $\mathrm{CDCl}_{3}$ ) was found to catalyze the formation of $\mathbf{4}$, reaching completion within $10 \mathrm{~min}$ at room temperature. On the other hand, the isolated oxazolidine $\mathbf{4}$ proved to be unstable in the absence of excess acetone, as its solution in wet $\mathrm{CDCl}_{3}$ slowly decomposed back to acetone and leucinol, presumably via enamine $6 / 7$ and/or imine 5 (ca 50\% conversion at room temperature within $24 \mathrm{~h}$ ).

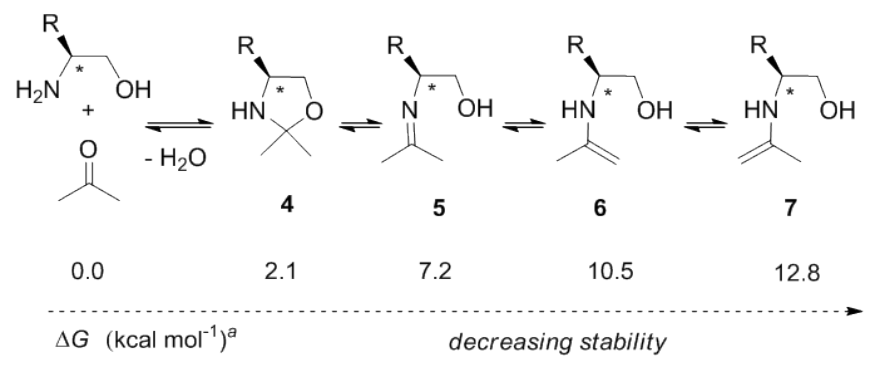

Scheme 2. Relative stability of reactive intermediates. $\mathrm{R}=\mathrm{i}-\mathrm{PrCH}_{2}(\mathbf{3 a})$ in the NMR study; $R=M e(3 b)$ in the calculations. [a] Calculated by using the $(\omega B 97 x d / c c-P V T Z+S M D) / /(\omega B 97 x d / c c-P V D Z+S M D)$ method.

Similar equilibria, involving analogous oxazolidinones derived from proline, i.e., from an amino acid (with a secondary amino group) rather than from an amino alcohol, have been observed before. ${ }^{[3,14,16]}$ These intermediates, to whose side the equilibrium is heavily shifted at the expense of the desired reactive enamines, have actually been shown to act as

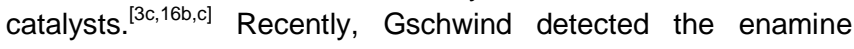
intermediate in the proline-catalyzed self-aldolization of propionaldehyde and demonstrated its formation from the corresponding oxazolidinone by detailed NMR studies. ${ }^{[17]}$ In her seminal papers, ${ }^{[17]}$ she also stated that enamines were only detected for aldehydes (though at low concentrations) but not for ketones, where the equilibrium is almost entirely shifted toward oxazolidinones due to the Thorpe-Ingold effect of the geminal alkyls. $^{[17,18]}$ In a subsequent paper, published after our preliminary communication ${ }^{[9]}$ and while this work was in progress, Gschwind demonstrated the formation of an oxazolidine intermediate (congener of 4) from prolinol and propionaldehyde. $^{[19]}$

Oxazolidine 4 has now been found to catalyze the aldol reaction of $1 \mathrm{a}$ with acetone in $\mathrm{CHCl}_{3}$ at $37{ }^{\circ} \mathrm{C}$ as efficiently as leucinol, with the same rate constant (at $20 \mathrm{~mol} \%$ catalyst loading). ${ }^{[20]}$ This observation is in a full agreement with the Gschwind NMR study, ${ }^{[17 a]}$ in which she showed that the prolinederived oxazolidinone generates the reactive enamine, confirming an earlier mechanism formulated by Seebach and Eschenmoser $^{[3 \mathrm{c}]}$ and Vilarrasa, ${ }^{[16 \mathrm{~d}]}$ according to which oxazolidinones should serve as reactive intermediates rather than "parasitic" species.

To rationalize the experimental observations and obtain complementary information, the latter aldol reaction was studied in silico by using the Gaussian 09 software (see the Experimental part for details). ${ }^{[21]}$ Here, for convenience, Lleucinol $\left(\mathbf{3} \mathbf{a}, \mathrm{R}=i-\mathrm{PrCH}_{2}\right)$ was replaced by $\mathrm{L}$-alaninol $(\mathbf{3} \mathbf{b}, \mathrm{R}=$ $\mathrm{Me}) .{ }^{[15]}$ Aiming at the quantitative accuracy of the computed data, a number of modern DFT functionals ${ }^{[22]}$ have been compared with the "golden standard" coupled cluster $\operatorname{CCSD}(T)$ ab initio method. We expected that coupling the $\operatorname{CCSD}(T)$ method with presumably one of the most accurate solvation method, COSMO-RS, ${ }^{[23]}$ should yield the quantitatively accurate data for the equilibrium between the species 4-7 in solution, i.e. in the process that we consider as the representative model capturing most of the essential changes of electronic structure studied here.

The results are summarized in Table 1, from which it can be concluded that the best correlation between the benchmark $\operatorname{CCSD}(\mathrm{T}) /$ def2-QZVP+COSMO-RS ${ }^{[23]}$ values and the tested DFT functionals was obtained for the $\omega B 97 \times d / c c-p V T Z$ method in combination with $\mathrm{SMD}^{[24]}$ solvation model (Table 1 ). In line with the studies by Clark and Tsogoeva, ${ }^{[23 e]}$ performing the geometry optimization with the $\omega B 97 \times d / c c-p V D Z$ method turned out to afford a better correlation with the $\operatorname{CCSD}(T)$ data than that attained by using the B3LYP/6-31g(d,p) method (compare methods $\mathbf{A}$ and $\mathbf{D}$, Table 1). Therefore, (wB97xd/cc-PVTZ + $\mathrm{SMD}) / /(\omega \mathrm{B} 97 \mathrm{xd} / \mathrm{cc}-\mathrm{PVDZ}+\mathrm{SMD})$ was employed as the method of choice for further calculations.

The computational study of the equilibrium mixture of the species 4-7 $(R=M e)$ arising from acetone and the catalyst revealed the energies of the individual molecules (Scheme 2). Here, oxazolidine $\mathbf{4}$ was identified as the most stable product, being, most likely, the catalyst resting state, whereas imine $\mathbf{5}$ is predicted to be less stable by $5.1 \mathrm{kcal} \mathrm{mol}^{-1}$. Most significantly, 
the syn-enamine 6 was found to be preferred over the antirotamer 7 by $2.3 \mathrm{kcal} \mathrm{mol}^{-1}$, which stands in stark contrast to the proline-derived enamines. ${ }^{[2,3,12,17]}$ Note that this scenario is systematically predicted by all the methods using the larger 6$311++g(2 d, p)$ and cc-pVTZ basis sets (see Table 1 and Supporting Information).

Table 1. Gibbs free energies of the 4-7 formation (Scheme 2; $\mathrm{R}=\mathrm{Me}$ ) in solution computed by methods A-D. ${ }^{[a, b]}$

\begin{tabular}{ccccc}
\hline species & A & B & C & D \\
\hline 4 & 2.1 & $7.9(6.2)$ & $0.3(-1.0)$ & 1.6 \\
5 & 7.2 & $7.6(5.5)$ & $5.7(3.3)$ & 7.4 \\
6 & 10.5 & $12.6(8.4)$ & $8.6(4.4)$ & 12.4 \\
7 & 12.8 & $14.9(10.4)$ & $11.0(6.5)$ & 14.7 \\
\hline
\end{tabular}

[a] The energies are given in $\mathrm{kcal} \mathrm{mol}^{-1}$; the values in columns A-C were calculated by using the SMD solvation model (values in parenthesis were calculated by using the CPCM/UAKS solvation model). [b] Methods: $A$ $\omega B 97 x d / c c-p V T Z / / \omega B 97 x d / c c-P V D Z ; \quad B, \quad B 3 L Y P / 6-311++g(2 d, p) / / B 3 L Y P / 6-$ 31g(d,p); C, M06-2X/cc-pVTZ//B3LYP/6-31g(d,p); D, CCSD(T)/def2-QZVP + COSMO-RS//B3LYP/6-31g(d,p)

Further calculations were performed to find the most plausible reaction pathway from oxazolidine 4 to the reactive enamine intermediates $\mathbf{6 / 7}$. No energetically accessible transition state could be located for direct transformation as a single elementary step. When a molecule of water was introduced into the system, transition states $\mathbf{8}$ and $\mathbf{9}$ (Scheme 3 , upper part) were found for the conversion of oxazolidine 4 into enamines $\mathbf{6}$ and 7, respectively; here, $\mathbf{8}$ is lower in energy than 9 by $0.4 \mathrm{kcal} \mathrm{mol}^{-1}\left(30.7 \mathrm{kcal} \mathrm{mol}^{-1} \mathrm{vs} 31.1 \mathrm{kcal} \mathrm{mol}^{-1}\right.$, respectively). ${ }^{[25]}$

Since isatin (1a) was experimentally found to catalyze the conversion of the amino alcohol $\mathbf{3}$ into oxazolidine $\mathbf{4}$ (vide supra), it is tempting to assume that $\mathbf{1 a}$ may also catalyze other interconversions between the intermediates 4-7. In support of this hypothesis, transition states $\mathbf{1 0}$ and $\mathbf{1 1}$ involving isatin (1a) were located for the reactions $4 \rightarrow 6$ and $\mathbf{4} \rightarrow \mathbf{7}$ (Scheme 3, bottom part). Note that in both instances isatin acts as a bidentate proton donor/acceptor, where the $\mathrm{N}-\mathrm{H}$ group offers its proton for promoting the cleavage of the $\mathrm{C}-\mathrm{O}$ bond of the oxazolidine, whereas its amidic carbonyl acts as a base in the abstraction of a proton from the methyl to generate the enamine structure. $\mathrm{TS}^{\neq} \mathbf{1 0}$, giving rise to the syn-enamine $\mathbf{6}$, was found to be by $0.4 \mathrm{kcal} \mathrm{mol}^{-1}$ higher in energy than its counterpart $\mathrm{TS}^{\neq} \mathbf{1 1}$ generating the anti-enamine $\mathbf{7}$, which represents quite the opposite preference (though rather marginal) compared to the water-mediated reaction. ${ }^{[26]}$ Importantly, both barriers of the isatin-catalyzed reactions (TS 10 and $\mathrm{TS}^{\neq} 11$ ), are by more than $4 \mathrm{kcal} \mathrm{mol}^{-1}$ lower than those for the water-catalyzed reactions, i.e., than $\mathrm{TS}^{\neq} \mathbf{8}$ and $\mathrm{TS}^{\neq} \mathbf{9}$ $\left(26.5\right.$ and $26.1 \mathrm{kcal} \mathrm{mol}^{-1}$ vs 30.7 and $31.1 \mathrm{kcal} \mathrm{mol}^{-1}$, respectively; Scheme 3). Based on these results, it can be concluded that the formation of enamines $6 / 7$ is catalyzed by the starting material of the reaction, i.e., by isatin (1a). The anti-enamine $\mathbf{7}$ is slightly kinetically favored over its syn- rotamer 6 (by $0.4 \mathrm{kcal} \mathrm{mol}^{-1}$ ) but is thermodynamically less stable (by $2.3 \mathrm{kcal} \mathrm{mol}^{-1}$ ). Therefore, under equilibrium conditions, the reaction can be predicted to proceed mainly via the syn-enamine 6 .

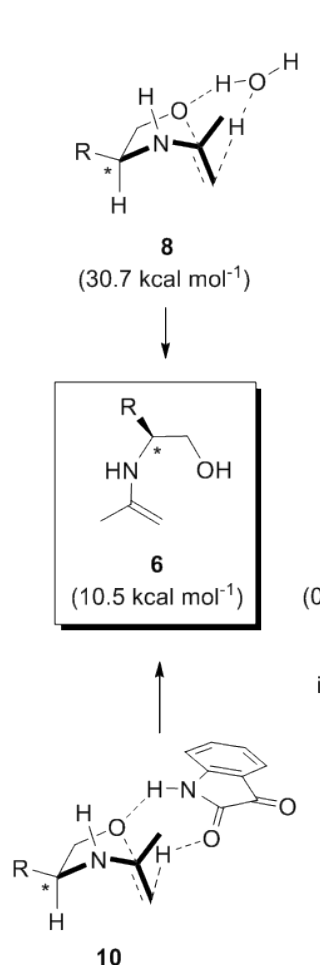

$\left(26.5 \mathrm{kcal} \mathrm{mol}^{-1}\right)$

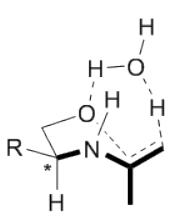

9<smiles>CC(C)O</smiles><smiles>[R]C1COC(C)(C)N1</smiles>

$\left(0.0 \mathrm{kcal} \mathrm{mol}^{-1}\right)$
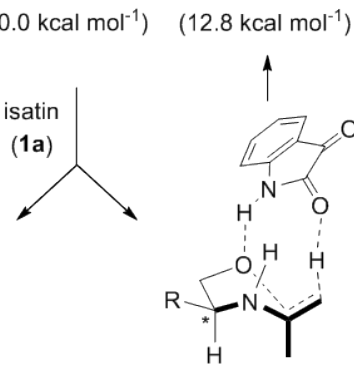

11

$\left(26.1 \mathrm{kcal} \mathrm{mol}^{-1}\right)$
Scheme 3. Formation of the syn- and anti-enamines 6 and 7 via 8 - 11. The computed values were obtained at the (wB97xd/cc-PVTZ+ $\mathrm{SMD}) / /(\omega \mathrm{B} 97 \times \mathrm{d} / \mathrm{cc}-\mathrm{PVDZ}+\mathrm{SMD})$ level of theory.

Computational investigation of the aldol step $(\mathbf{1 a}+\mathbf{6 / 7} \rightarrow \mathbf{2 a})$ indicates that syn-enamine $\mathbf{6}$ should produce $(S)-2 \mathbf{a}$, since the pathway toward its enantiomer would require overcoming an activation barrier that is higher by $10.6 \mathrm{kcal} \mathrm{mol}^{-1}$ (Scheme 4, left part, and Figure 1). By contrast, anti-enamine 7 (disfavored thermodynamically, vide supra) would predominantly produce $(R)-2 \mathrm{a}$, as the corresponding transition state is preferred by 2.4 kcal mol ${ }^{-1}$ over that generating (S)-2a (Scheme 4, right part; Figure 1). In other words, the syn-enamine 6 should produce mainly (S)-2a (via the transition state 12), whereas its antirotamer 7 would predominantly afford $(R)-\mathbf{2 a}$ (via the transition state 13).

The barrier for the syn-anti enamine interconversion via the transition state 14 was found to be relatively low $\left(9.7 \mathrm{kcal} \mathrm{mol}^{-1}\right.$ for the $\mathbf{6} \rightarrow \mathbf{7}$ transformation and $7.4 \mathrm{kcal} \mathrm{mol}^{-1}$ for the $\mathbf{7} \rightarrow \mathbf{6}$ transformation; Scheme 3 and Figure 1). As that barrier is considerably lower than the activation energy of the aldol step (compare $7.4 \mathrm{kcal} \mathrm{mol}^{-1}$ and $9.7 \mathrm{kcal} \mathrm{mol}^{-1}$ vs $11.9 \mathrm{kcal} \mathrm{mol}^{-1}$ and $11.6 \mathrm{kcal} \mathrm{mol}^{-1}$; Scheme 4), the thermodynamic equilibrium between $\mathbf{6}$ and $\mathbf{7}$ should settle quickly in favor of $\mathbf{6}$, and the system can be viewed as obeying the Curtin-Hammett principle (Figure 1). ${ }^{[27]}$ Accordingly, the $\Delta \Delta G^{\neq}$for the aldol step is $2.6 \mathrm{kcal}$ 
$\mathrm{mol}^{-1}\left[(11.9-11.6)+(10.7-8.4)=2.6 \mathrm{kcal} \mathrm{mol}^{-1}\right.$; Scheme 4 and Figure 1] in favor of (S)-2a, consistent with the experiment.

This analysis can also account for the experimentally observed initial formation of a nearly racemic product, apparently resulting from a different catalytic process, possibly using free leucinol. ${ }^{[28]}$ Before the Curtin-Hammett equilibrium is attained, the concentration of enamine 7 can be higher (note that 7 is kinetically slightly preferred over 6; Scheme 4), which results in more $(R)-\mathbf{2 a}$ being produced via the transition state $\mathbf{1 3}$ (Scheme 4). As soon as all the leucinol is consumed by conversion into oxazolidine 4 , the reaction follows the scenario shown in Scheme 4 and (S)-2a is produced almost exclusively.

A moderate primary kinetic isotope effect $(\mathrm{KIE})^{[29]}\left(k_{H} / k_{\mathrm{D}}=\right.$ 2.7) was observed for the reaction of isatin (1a) with $d_{6}$-acetone, catalyzed by L-leucinol, implying that the enamine formation can be the rate determining step. ${ }^{[30]}$ This is consistent with the DFT calculations (Figure 1), showing that the activation energy of the enamine formation is the highest point on the computed reaction pathway (26.1 vs 18.1 and $20.0 \mathrm{kcal} \mathrm{mol}^{-1}$; Figure 1). ${ }^{[1]}$ Hence, both the calculations and the KIE suggest that the rate-limiting step in this case precedes the aldol step. This is understandable as $1 \mathbf{a}$ is a highly activated electrophile, so that the aldol step can become faster than the enamine formation. ${ }^{[32,33]}$

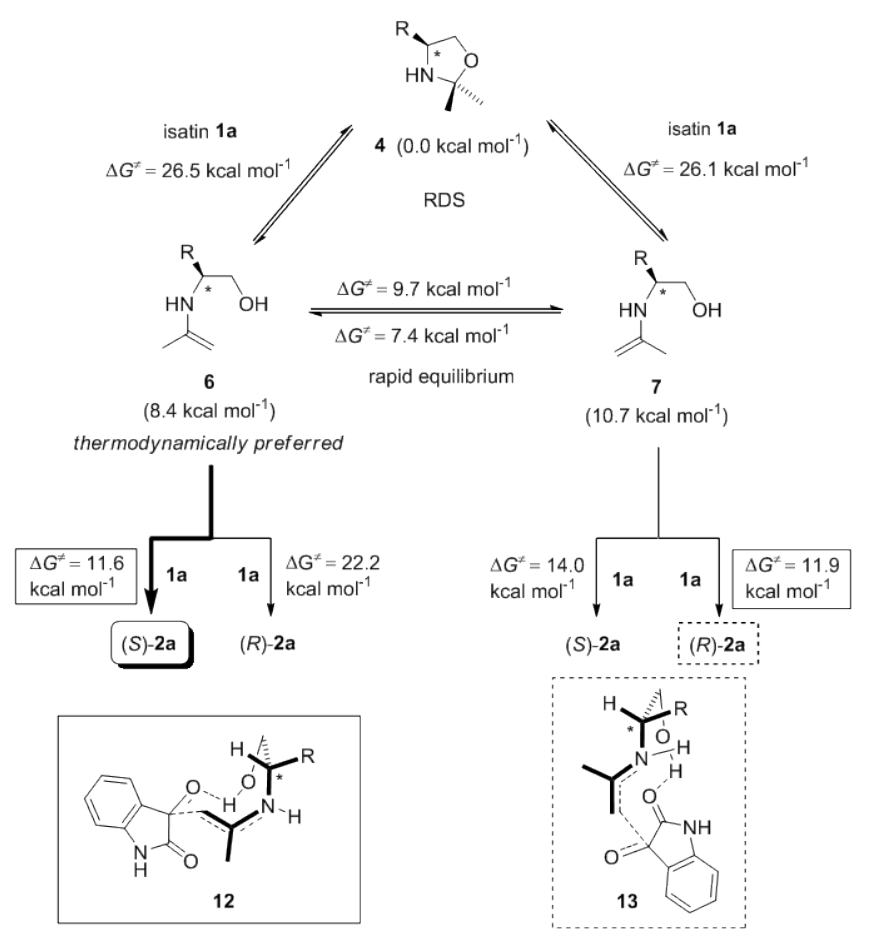

Scheme 4. The aldol reaction mechanism. $R=$ Me. Computed values were

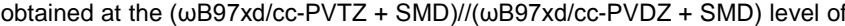
theory.

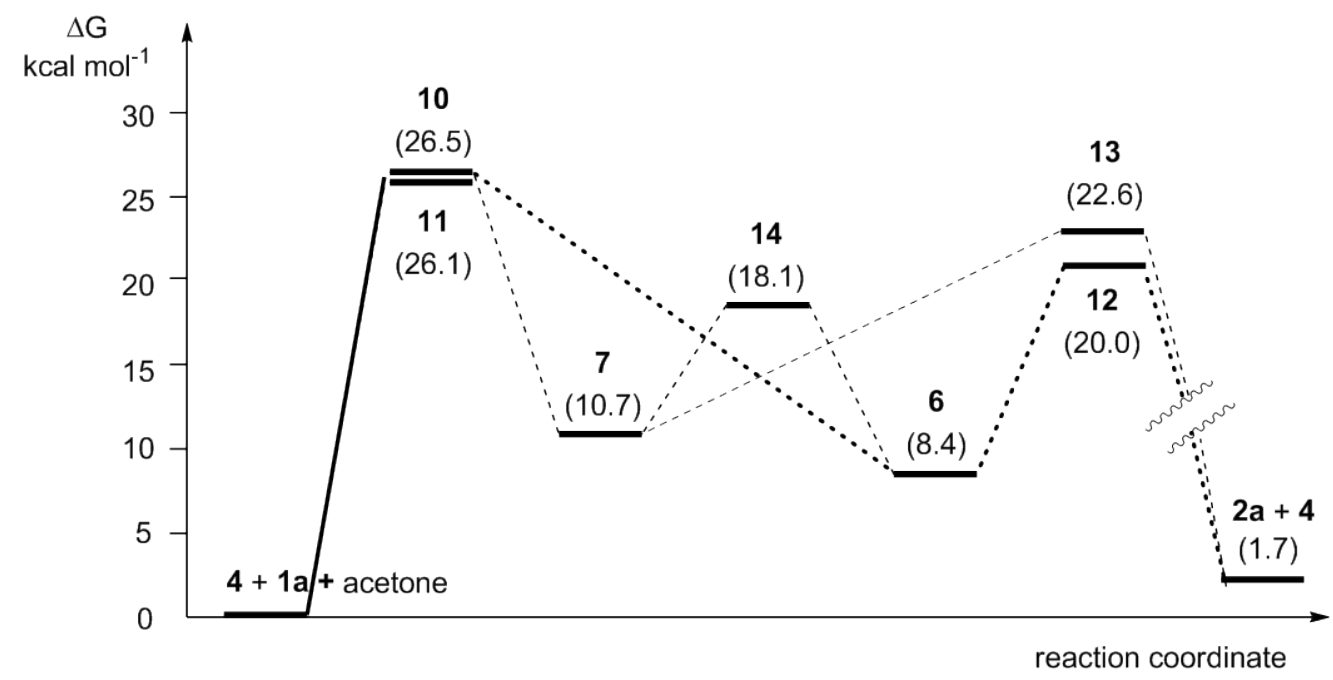

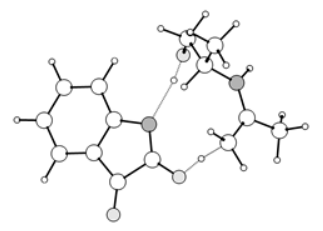

10

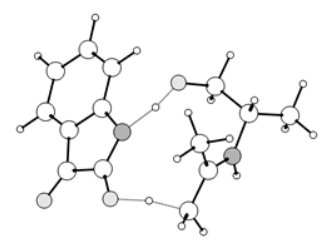

11

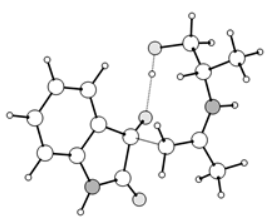

12

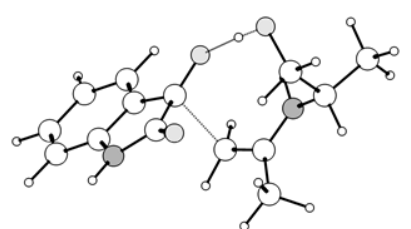

13

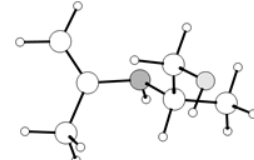

14

Figure 1. The calculated reaction pathway for the formation of $2 \mathrm{a}$ from 4 (Scheme 3 and $4 ; \mathrm{R}=\mathrm{Me}$ ). The preferred pathway is marked bold. 
Importantly, the barrier for the enamine 6/7 isomerization $\left(\mathrm{TS}^{\neq}\right.$14; Figure 1) is lower than the $\mathrm{TS}^{\neq} 12$ of the aldol step. Hence, in agreement with the Curtin-Hammett principle, the system thus produces (S)-2a with high enantioselectivity. As isatin (1a) catalyzes the rate-determining formation of enamine 6/7, the reaction should be 1st order in isatin, which is in agreement with the experiment. Notably, Figure 1 clearly shows that the reaction is "up-hill", i.e., that the final aldol product $\mathbf{2 a}$ is higher in energy than oxazolidine 4 (and consequently higher than the staring isatin 1a). Under the equilibrium conditions, the reaction is obviously driven to completion by a large excess of acetone as one of the starting materials.

\section{Conclusions}

In conclusion, L-leucinol (3a), a primary amino alcohol, has been shown to serve as an efficient, enantioselective organocatalyst for the cross-aldol reaction of isatin 1a (an activated, non-enolizable ketone) with acetone (an enolizable, less electrophilic ketone). The reaction proceeds at room temperature with a trace of water in $\mathrm{CH}_{2} \mathrm{Cl}_{2}$ as an optimal solvent, at 10-20 mol\% catalyst loading (Scheme 1). Mechanistic and computational studies unraveled the initial formation of oxazolidine 4 that has been identified as the catalyst resting state; its formation turned out to be dramatically accelerated by the starting isatin, so that in its presence practically all of the leucinol is converted into 4 within 10-15 min (Scheme 2). Conversion of the latter oxazolidine into the reactive synenamine 6, also catalyzed by isatin (acting as a bidentate hydrogen-bond donor/acceptor), is rate determining as demonstrated by both the calculations $\left(\Delta G^{\neq}=26.1 \mathrm{kcal} \mathrm{mol}^{-1}\right.$ for the analogous L-alaninol $\mathbf{3} \mathbf{b}, \mathrm{R}=\mathrm{Me}$ ) and the isotope effect $\left(k_{H} / k_{\mathrm{D}}=2.7\right.$ observed for the reaction using $d_{6}$-acetone). The calculated barrier of $26.1 \mathrm{kcal} / \mathrm{mol}$ compares well with the experimental reaction half life of $210 \mathrm{~min}(\mathrm{R}=i-\mathrm{Bu}$; for more details see Isotope Effect Experiment below) that corresponds to $23.2 \mathrm{kcal} \mathrm{mol}^{-1}$, estimated by Eyring equation. We expect that the calculated barrier would be further lowered by $\sim 1 \mathrm{kcal} \mathrm{mol}^{-1}$ if tunneling corrections were taken into consideration. ${ }^{[34]}$ Therefore, the agreement between the experimental and computed "absolute" activation energies is within $2 \mathrm{kcal} / \mathrm{mol}$ which provides further evidence for the presented reaction mechanism. According to the calculations, the syn-enamine $\mathbf{6}$ is thermodynamically favored over its anti-rotamer 7 by $2.3 \mathrm{kcal}$ $\mathrm{mol}^{-1}$ (Scheme 3 and Figure 1). The subsequent aldol reaction of $\mathbf{6}$ with isatin via $\mathrm{TS}^{\neq} \mathbf{1 2}$ (the pathway marked bold in Scheme 4 and Figure 1) produces (S)-2a (calculated $\Delta G^{\neq}=11.6 \mathrm{kcal}$ $\mathrm{mol}^{-1}$ ), which is kinetically favored over the formation of its enantiomer (calculated $\Delta \Delta G^{f}=10.6 \mathrm{kcal} \mathrm{mol}^{-1}$ ). The overall stereochemical outcome of this aldol reaction is thus determined by the Curtin-Hammett scenario with the equilibrium between syn- and anti-enamines 6 and 7 settled relatively quickly due to the low energy of the corresponding TS $^{\neq} 14$ (Figure 1). The preferential formation of the syn-enamine $\mathbf{6}$ is noteworthy as it stands in sharp contrast to the well-established anti-enamine generation from proline $e^{[3,12,17]}$ and could thus be regarded as a characteristic feature of primary amino alcohols. Equally notable is the catalytic role of isatin (1a) in the formation of oxazolidine 4 and enamine $\mathbf{6}$, so that it can be regarded as both the starting material and co-catalyst.

The difference in the calculated activation energies for the $(R)$ - and (S)-channels suggest $\geq 99 \%$ ee in favor of (S)-2a, whereas only $94 \%$ ee was observed experimentally. This discrepancy can be ascribed to the early stages of the reaction, which were shown to be much less enantioselective, presumably due to a different mechanism operating before the CurtinHammett equilibrium is established.

In summary, this study suggests that the overall stereochemistry of the aldol reaction of isatin with acetone is controlled by two key events: (1) the isatin-catalyzed formation of the syn-enamine 6; and (2) the high preference of the synenamine $\mathbf{6}$ to produce $(S)-\mathbf{2} \mathbf{a}$ on reaction with isatin (1a).

\section{Experimental Section}

\section{Computational details}

Geometries of all structures (minima and saddle points) were optimized at the B3LYP/6-31g(d,p) and wB97xd/cc-PVDZ levels in vacuum or in a solvent (using the SMD solvation model); subsequent vibrational frequency calculations were performed at the same level for all calculated structures. All transition states thus found possess exactly one negative Hessian eigenvalue, while all other stationary points were confirmed to be genuine minima on the potential energy surface (PES) Intrinsic reaction coordinate (IRC) analysis was performed to unambiguously assign located transition states for all the potential reaction pathways. Electronic energies were obtained by performing single point calculations at the $\omega B 97 \times d / c c-p V T Z$ level (unless stated otherwise) in solvent or in vacuum. Enthalpies are reported as sums of $\triangle E$, zero point vibrational energy (ZPVE) corrections, and thermal corrections at $298 \mathrm{~K}$. Gibbs energies were calculated as $\Delta G=\Delta H-\mathrm{T} \Delta S$ at $298 \mathrm{~K}$ where enthalpies and entropies were obtained by using standard statistical mechanical formulae for the ideal gas, rigid rotor, and harmonic oscillator approximations following the normal-mode analysis in vacuum. The benchmark reaction energies and Gibbs energies were obtained using $\operatorname{CCSD}(\mathrm{T}) / \mathrm{def} 2-\mathrm{QZVP}{ }^{[23 \mathrm{~b}]}$ calculations and Turbomole software. ${ }^{[23 a, c]}$ in combination with Klamt's conductor-like screening model for realistic solvation (COSMO-RS) ${ }^{[23 d]}$ COSMO-RS calculations were carried out using cosmotherm software and the recommended protocol: BP86/def-TZVP geometry optimizations in vacuo and in ideal conductor $(e=\infty)$ followed by the COSMO-RS calculations in the target solvent $\left(\mathrm{CH}_{2} \mathrm{Cl}_{2}\right)$. A correction of $(1.9 \cdot \Delta n) \mathrm{kcal} \mathrm{mol}^{-1}$ (corresponding to the difference between the concentration of the ideal gas at $298 \mathrm{~K}$ and $1 \mathrm{~atm}$ and its $1 \mathrm{~mol} \mathrm{I}^{-1}$ concentration; $\Delta n$ is the change in number of moles in the reaction) has been applied in order that the computed values refer to 1 $\mathrm{mol} \mathrm{I}^{-1}$ standard state.

\section{Isotope Effect Experiment}

Isatin $1 \mathrm{a}$ (16 $\mathrm{mg}, 0.11 \mathrm{mmol})$ was added in one portion to a solution of Lleucinol $(2.5 \mathrm{mg}, 0.02 \mathrm{mmol}), \mathrm{H}_{2} \mathrm{O}(3.8 \mathrm{mg}, 0.22 \mathrm{mmol})$, and acetone $(0.25 \mathrm{~mL})$ in dichloromethane- $d_{2}(1 \mathrm{~mL})$ at room temperature, the reaction mixture was transferred into an NMR tube, and monitored by ${ }^{1} \mathrm{H}$ NMR spectroscopy at $24{ }^{\circ} \mathrm{C}$. Linear relationship was found between $\ln \left[c\right.$ (isatin) $/ c_{0}$ (isatin) $]$ and the reaction time, indicating the first order of the reaction. The reaction half-life was found to be $210 \mathrm{~min}$. In a parallel experiment, isatin $1 \mathrm{a}$ (16 $\mathrm{mg}, 0.11 \mathrm{mmol})$ was added in one portion to a solution of L-leucinol (2.5 mg, $0.02 \mathrm{mmol}), \mathrm{H}_{2} \mathrm{O}$ (3.8 mg, $\left.0.22 \mathrm{mmol}\right)$, and 
acetone- $d_{6}(0.25 \mathrm{~mL})$ in dichloromethane- $d_{2}(1 \mathrm{~mL})$ at room temperature, the reaction mixture was transferred into an NMR tube, and monitored by ${ }^{1} \mathrm{H}$ NMR spectroscopy at $24{ }^{\circ} \mathrm{C}$. Linear relationship was found again between $\ln \left[c\right.$ (isatin) $/ c_{0}$ (isatin)] and the reaction time, indicating the first order of the reaction. The reaction half-life was found to be $570 \mathrm{~min}$. Comparison of the two experiments gives $\mathrm{KIE}=t_{1 / 2}($ reaction 2) $/$ $t_{1 / 2}($ reaction 1$)=2.7$. Conversion graphs with linear regression analyses are provided in $\mathrm{SI}$

\section{Acknowledgements}

We thank the Loughborough University, the University of Cambridge and EPSRC (EP/K009494/1) for supporting this research. Further support was obtained from the Axel WennerGren Foundation, the Grant Agency of the Czech Republic (grant 14-31419S), and the COST office via the ORCA action CM905. An allocation of computer time on the Western Canada Research Grid (WestGrid) is also gratefully acknowledged. Y. V. S. acknowledges the support via the Newton International Alumni Scheme from the Royal Society.

Keywords: organocatalysis - self-catalysis $\cdot$ computational studies $\bullet$ enamines $\bullet$ isatins $\bullet$ oxazolidines

[1] For the pioneering work on the stoichiometric use of enamines, see: (a) G. Stork, R. Terrell, J. Szmuszkovicz, J. Am. Chem. Soc. 1954, 76, 2029-2030; (b) G. Stork, H. K. Landesman, J. Am. Chem. Soc. 1956 78, 5128-5129. For overviews on catalytic aldol reactions proceeding via enamines, see: (c) R. Mahrwald, B. Costisella, B. Gündogan Synthesis 1998, 262-264; (d) B. List, Amine-Catalyzed Aldol Reactions In Modern Aldol Reactions (Ed.: R. Mahrwald); Wiley-VCH: Weinheim, 2004, Vol 1, p 161; (e) E. M. Carreira, A. Fettes, C. Marti, Org. React 2006, 67, 1-216; (f) A. Berkessel, H. Gröger in Asymmetric Organocatalysis, Wiley-VCH, Weinheim, 2005; (g) P. Melchiorre, M Marigo, A. Carlone, G. Bartoli, Angew. Chem. Int. Ed. 2008, 47, 61386171; (h) M. Nielsen, D. Worgull, T. Zweifel, B. Gschwend, S Bertelsen, K. A. Jørgensen, Chem. Commun. 2011, 632-649; (i) H. Jiang, Ł. Albrecht, G. Dickmeiss, K. L. Jensen, K. A. Jørgensen in Organocatalysis In Comprehensive Enantioselective Organocatalysis Catalysts, Reactions, and Applications (Ed.: P. I. Dalko), Wiley-VCH, Weinheim, 2013, Vol 1, p 33

[2] (a) B. List, R. A. Lerner, C. F. Barbas, J. Am. Chem. Soc. 2000, 122 2395-2396; (b) S. Mukherjee, J. W. Yang, S. Hoffmann, B. List, Chem. Rev. 2007, 107, 5471-5569; (c) F. Tanaka, C. F. Barbas in Enantioselective Organocatalysis (Ed.: P. I. Dalko), Wiley- $\mathrm{VCH}$, Weinheim, 2007, p. 19; (d) N. Mase, C. F. Barbas in Comprehensive Enantioselective Organocatalysis - Catalysts, Reactions, and Applications (Ed.: P. I. Dalko), Wiley-VCH, Weinheim, 2013, Vol 3, p 793. (e) R. B. Sunoj in Comprehensive Enantioselective Organocatalysis - Catalysts, Reactions, and Applications (P. I. Dalko, Ed.), Wiley-VCH, Weinheim, 2013, Vol 2, p 465.

[3] (a) P. H.-Y. Cheong, K. N. Houk, J. Am. Chem. Soc. 2004, 126, 13912 13913; (b) C. Allemann, R. Gordillo, F. R. Clemente, P. H.-Y. Cheong K. N. Houk, Acc. Chem. Res. 2004, 37, 558-569; (c) D. Seebach, A. K. Beck, D. M. Badine, M. Linbach, A. Eschenmoser, A. M. Treasurywala R. Hobi, W. Prikoszovich, B. Linder, Helv. Chim. Acta 2007, 90, 425471. For the detection and or isolation of enamine intermediates, see (d) S.-I. Yamada, G. Otani, Tetrahedron Lett. 1969, 10, 4237-4240; (e) D. Seebach, U. Groselj, D. M. Badine, W. B. Schweizer, A. K. Beck Helv. Chem. Acta 2008, 91, 1999-2034; (f) T. J. Peelen, Y. Chi, S. H Gellman, J. Am. Chem. Soc. 2005, 127, 11598-11599; (g) U. Groselj,
D. Seebach, D. M. Badina, W. B. Schweizer, A. K. Beck, I. Krossing, P. Klose, Y. Hayashi, T. Uchimaru, Helv. Chim. Acta 2009, 92, 1225-1259 For the X-ray structure of proline-derived enamines, see: (h) D. A. Bock, C. W. Lehmann, B. List, Proc. Nat. Acad. Sci. 2010, 107, 2063620641.

[4] The amino alcohols, reported to date as organocatalysts, typically featured a secondary amine moiety, whereas the diamines usually contained a combination of one secondary and one tertiary amino group or one primary and one tertiary: (a) G. Zhong, J. Fan, C. F. Barbas, Tetrahedron Lett. 2004, 45, 5681-5684; (b) T. Bui, C. F. Barbas, Tetrahedron Lett. 2000, 41, 6951-6954; (c) T. Kano, M. Ueda, J. Takai, K. Maruoka, J. Am. Chem. Soc. 2006, 128, 6046-6047; (d) S Luo, H. Xu, J. Li, L. Zhang, J.-P. Cheng, J. Am. Chem. Soc. 2007, 129, 3074-3075; (e) N. Mase, K. Watanabe, H. Yoda, K. Takabe, F. Tanaka C. F. Barbas, J. Am. Chem. Soc. 2006, 128, 4966-4967; For overviews of diamine organocatalysts, see: (f) W. Notz, F. Tanaka, C. F. Barbas, Acc. Chem. Res. 2004, 37, 580-590; (g) L.-W. Xu, Y. Lu in Comprehensive Enantioselective Organocatalysis - Catalysts, Reactions, and Applications (P. I. Dalko, Ed.), Wiley-VCH, Weinheim: 2013; Vol 1, p 51; (h) H. Kotsuki, N. Sasakura in Comprehensive Enantioselective Organocatalysis - Catalysts, Reactions, and Applications (P. I. Dalko, Ed.), Wiley-VCH, Weinheim: 2013; Vol 1, p 3.

[5] For low catalyst loading in enamine catalysis, see: (a) M. Wiesner, G Upert, G. Angelici, H. Wennemers, J. Am. Chem. Soc. 2010, 132, 6-7 (b) P. Krattiger, R. Kovasy, J. D. Revell, S. Ivan, H. Wennemers, Org Lett. 2005, 7, 1101-1103; (c) J. D. Revell, H. Wennemers, Tetrahedron 2007, 63, 8420-8424; (d) J. D. Revell, H. Wennemers, Adv. Synth Catal. 2008, 350, 1046-1054; (e) M. Wiesner, J. D. Revell, H. Wennemers, Angew. Chem. Int. Ed. 2008, 47, 1871-1874; (f) M Wiesner, J. D. Revell, S. Tonazzi, H. Wennemers, J. Am. Chem. Soc 2008, 130, 5610-5611. (g) M. Wiesner, M. Neuburger, H. Wennemers Chem. Eur. J. 2009, 15, 10103-10109; (h) M. Wiesner, H. Wennemers, Synthesis 2010, 1568-1571; For an overview, see: (i) R. Fanelli, U Piarulli in Comprehensive Enantioselective Organocatalysis Catalysts, Reactions, and Applications (Ed.: P. I. Dalko), Wiley-VCH Weinheim: 2013; Vol 1, p 97

[6] For the use of amino acids with a primary amino group and other primary amines as catalysts for aldol reaction, see, e.g.: (a) U. Eder, G. Sauer, R. Wiechert, Angew. Chem., Int. Ed. Eng. 1971, 10, 496-497 (b) F. Tanaka, R. Thayumanava, N. Mase, C. F. Barbas, Tetrahedron Lett. 2004, 45, 325-328; (c) S. B. Tsogoeva, S. Wei, Tetrahedron: Asymmetry 2005, 16, 1947-1951; (d) A. L. Weber, S. Pizzarello, Proc. Natl. Acad. Sci. USA 2006, 103, 12713 - 12717; (e) A. Córdova, W. Zou, P. Dziedzic, I. Ibrahem, E. Reyes, Y. Xu, Chem. Eur. J. 2006, 12, 5383-5397 and references therein; (f) S. S. V. Ramasastry, H. Zhang, F. Tanaka, C. F. Barbas, J. Am. Chem. Soc. 2007, 129, 288-289; (g) J. Zhou, V. Wakchaure, P. Kraft and B. List, Angew. Chem. Int. Ed. 2008, 47, 7656-7658. (h) C. Arróniz, C. Escolano, F. J. Luque, J. Bosch, M. Amat, Org. Biol. Chem. 2011, 9, 5079-5085; (i) J. Li, S. Luo, J.-P. Cheng, J. Org. Chem. 2009, 74, 1747-1750; (j) X. Ma, C.-S. Da, L. Yi, Y.-N. Jia, Q.-P. Guo, L.-P. Che, F.-C. Wu, J.-R. Wang, W.-P. Li, Tetrahedron: Asymmetry 2009, 20, 1419-1424; (k) C.-S. Da, L.-P Che, Q.-P. Guo, F.-C. Wu, X. Ma, Y.-N. Jia, J. Org. Chem. 2009, 74, 2541-2546; (I) C. Shen, F. Shen, H. Xia, P. Zhang, X. Chen Tetrahedron: Asymmetry 2011, 22, 708-712; For recent reviews, see ref $[4 \mathrm{~g}]$ and the following: $(\mathrm{m}) \mathrm{V}$. Bisai, A. Bisai, V. K. Singh Tetrahedron 2012, 68, 4541-4580; (n) P. Melchiorre, Angew. Chem. Int. Ed. 2012 51, 9748-9770. For the use of the ValHis dipeptide (i.e., a primary amine) in Michael addition, see: (o) S. B. Tsogoeva, S. B. Jagtap, Synlett 2004, 2624-2626

[7] (a) O. Tokuda, T. Kano, W.-G. Gao, T. Ikemoto and K. Maruoka, Org Lett. 2005, 7, 5103-5105; (b) Z. Tang, L-F. Cun, X. Cui, A.-G. Mi, Y.-Z Jiang, L.-Z. Gong, Org. Lett. 2006, 8, 1263-1266; (c) S. Samanta and C.-G. Zhao, Tetrahedron Lett. 2006, 47, 3383-3386; (d) J. Yang, T. Wang, Z. Ding, Z. Shen, Y. Zhang, Org. Biomol. Chem. 2009, 7, 22082213 
[8] As a rule, the ketone-ketone aldol reactions proceed only to low conversions. A remedy is to continuously remove the product from the equilibrium, as in the classical example of dimerization of acetone using barium hydroxide in a Soxhlet extractor (which, however, cannot be used in our case): J. B. Conant, N. Tuttle, Org. Synth. 1941, Coll. Vol. $1,199$.

[9] A. V. Malkov, M. A. Kabeshov, M. Bella, O. Kysilka, D. A. Malyshev, K. Pluháčkova, P. Kočovský, Org. Lett. 2007, 9, 5473-5476.

[10] For the reaction of isatin with acetone catalyzed by proline, which exhibits poor enantiselectivity, see: (a) G. Luppi, P. G. Cozzi, M. Monari, B. Kaptein, Q. B. Broxterman, C. Tomasini, J. Org. Chem. 2005, 70, 7418-7421; For other aldol reactions of isatin, including the syntheses of Convolutamydine $A$, see the ref section in [9] and the following: (b) Q. Guo, M. Banushali, C.-G. Zhao, Angew. Chem. Int. Ed. 2010, 49, 9460-9464; (c) A. Suresh, N. Molleti, R. Panem, V. K. Singh Tetrahedron Lett., 2011, 52, 4080-4083; (d) Y. Liu, P. Gao, J. Wang, Q. Sun, Z. Ge, R. Li, Synlett 2012, 23, 1031-1034; (e) H. Liu, H. Wu, Z. Luo, J. Shen, G. Kang, B. Liu, Z. Wan, J. Jiang, Chem. Eur. J., 2012 18, 11899-11903. (f) S. Wei, B. Schmid, F. Z. Macaev, S. N. Curlat, A V. Malkov, S. B. Tsogoeva, Asymm. Catal. 2015, 2, 1-6. For a genera overview on chiral thiourea-type catalysts, see: (g) G. Jakab and P. R. Schreiner, Brønsted Acids: Chiral (Thio)urea Derivatives In Comprehensive Enantioselective Organocatalysis - Catalysts, Reactions, and Applications (Ed.: P. I. Dalko), Wiley-VCH, Weinheim 2013; Vol 2, p 315.

[11] Natural convolutamydine A, an anti-leukemia agent isolated from the marine bryozoan species Amathia convoluta, is $(R)$-configured: (a) $\mathrm{Y}$ Kamano, H. Zhang, Y. Ichihara, H. Kizu, K. Komiyama, G. R Pettit Tetrahedron Lett. 1995, 36, 2783-2784; (b) H. Takayama, T. Shimizu, H. Sada, Y. Harada, M. Kitajima and N. Aimi, Tetrahedron 1999, 55, 6841-6846.

[12] (a) L. Hoang, S. Bahmanyar, K. N. Houk, B. List, J. Am. Chem. Soc. 2003, 125, 16-17; (b) F. R. Clemente, K. N. Houk, Angew. Chem. Int Ed. 2004, 43, 5766-5768; (c) P. H. Y. Cheong, H. L. Zhang, R. Thayumanavan, F. Tanaka, K. N. Houk, C. F. Barbas, Org. Lett. 2006 8, 811-814; (d) S. Mitsumori, H. Zhang, P. H.-Y. Cheong, K. N. Houk, F. Tanaka, C. F. Barbas, J. Am. Chem. Soc. 2006, 128, 1040-1041; (e) Y. - H. Lam, K. N. Houk, U. Scheffler, R. Mahrwald, J. Am. Chem. Soc. 2012, 134, 6286-6295; (f) B. List, L. Hoang, H. J. Martin, Proc. Natl. Acad. Sci. 2004, 101, 5839-5842; (g) For recent DFT calculations on the proline-catalyzed aldol reaction, see: M. J. Ajitha, C. H. Suresh, J. Mol. Catal. A. 2011, 345, 37-43; (h) A. Armstrong, R. A. Boto, P Dingwall, J. Contreras-García, M. J. Harvey, N. J. Mason, H. S. Rzepa, Chem. Sci. 2014, 5, 2057-2071.

[13] For DFT studies of the proline-catalyzed aldol reaction of isatins with acetone in vacuo, see: (a) R. J. Corrêa, S. J. Garden, G. Angelici, C. Tomasini, Eur. J. Org. Chem. 2008, 736-744; (b) G. Luppi, M. Monari, R. J. Corrêa, F. de A. Violante, A. C. Pinto, B. Kaptein, Q. B. Broxterman, S. J. Garden, C. Tomasini, Tetrahedron 2006, 62, 12017 12024.

[14] For reports on the accelerating effect of water on the proline-catalyzed aldol reactions, see ref [2] and the following: (a) A. I. Nyberg, A. Usano, P. M. Pihko, Synlett 2004, 1891-1896; (b) P. M. Pihko, K. M Laurikainen, A. Usano, A. J. Nyberg, J. A. Kaavi, Tetrahedron 2006, 62 317-328; (c) Y. Hayashi, Angew. Chem. Int. Ed. 2006, 45, 8103-8104 (d) J.-F. Zhao, L. He, J. Jiang, Z. Tang, L.-F. Cun, L. Z. Gong Tetrahedron Lett. 2008, 49, 3372-3375. For the effect of other additives, see: (e) Y. Zhou, Z. Shan, J. Org. Chem. 2006, 71, 95109512; (f) C. J. Rogers, T. J. Dickerson, K. D. Janda, Tetrahedron 2006, 62, 352-356; (g) N. Mase, Y. Nakai, N. Ohara, H. Yoda, K. Takabe, F. Tanaka, C. F. Barbas, J. Am. Chem. Soc. 2006, 128, 734-735; (h) X.-H. Chen, S.-W. Luo, Z. Tang; L.-F. Cun, A.-Q. Mi, Y.-Z. Jiang, L.-Z. Gong, Chem. Eur. J. 2007, 13, 689-701; (i) N. Zotova, A. Franzke, A. Armstrong, D. G. Blackmond, J. Am. Chem. Soc. 2007, 129, 15100 15101. For an overview, see: (j) F. Giacalone, M. Gruttadauria in Comprehensive Enantioselective Organocatalysis - Catalysts,
Reactions, and Applications (P. I. Dalko, Ed.), Wiley-VCH, Weinheim: 2013; Vol 2, p 673. (k) For the effect of water on the aldol reaction of isatin with acetone, see ref $[6 \mathrm{n}]$ and the following: (I) G. Angelici, R. J. Corrêa, S. J. Garden, C. Tomasini, Tetrahedron Lett. 2009, 50, 814 817.

[15] L-Alaninol (3b) was found to be almost as efficient as L-leucinol (3a) providing (S)-2a with $90 \%$ ee

[16] (a) F. Orsini, F. Pelizzoni, M. Forte, M. Sisti, G. Bombieri, F. Benetollo, J. Heterocycl. Chem. 1989, 26, 837-841; (b) H. Iwamura, S. P. Mathew, D. G. Blackmond, J. Am. Chem. Soc. 2004, 126, 11770-11771; (c) H. Iwamura, D. H. Wells, S. P. Mathew, M. Klussmann, A. Armstrong, D G. Blackmond, J. Am. Chem. Soc. 2004, 126, 16312-16313; (d) C Isart, J. Bures, J. Vilarrasa, Tetrahedron Lett. 2008, 49, 5414-5418; (e) Y.-F. Hu, X. Lu, J. Struct. Chem. 2008, 27, 547-552; For kinetic evidence for the formation of oxazolidinones, see: (f) T. Kanzian, S. Lakhdar, H. Mayr, Angew. Chem. Int. Ed. 2010, 49, 9526-9529.

[17] (a) M. B. Schmid, K. Zeitler, R. M. Gschwind, Angew. Chem. Int. Ed. 2010, 49, 4997-5003; (b) M. B. Schmid, K. Zeitler, R. M. Gschwind, J. Org. Chem. 2011, 76, 3005-3015.

[18] Aprotic solvents, such as MeCN, DMSO, and DMF were found to stabilize the proline-derived enamines via hydrogen bonding between the carboxyl group and the solvent, allowing their detection by NMR spectroscopy. On the other hand, protic solvents, such as $\mathrm{MeOH}$, can provide hydrogen-bonding stabilization of isoxazolidinones and, as a results, the enamine concentration drops below the NMR detection. ${ }^{[17]}$

[19] (a) M. B. Schmid, K. Zeitler, R. M. Gschwind, J. Am. Chem. Soc. 2011 133, 7065-7074. For a detailed NMR analysis of the enamine intermediates, see: (b) M. B. Schmid, K. Zeitler, R. M. Gschwind, Chem. Sci. 2011, 2, 1793-1803. For stabilization of the proline-derived enamine by bases, see: (c) M. B. Schmidt, K. Zeitler, R. M. Gschwind, Chem. Eur. J. 2012, 18, 3362-3370.

[20] Autocatalysis by the product $\mathbf{2} \mathbf{a}$ was ruled out by a control experiment, carried out in the presence of (S)-(-)-2a (20 mol\%), added at the onse of the reaction. The latter additive neither catalyzed the reaction nor it altered the enantiomeric ratio of the gradually produced $2 \mathrm{a}$ when $\mathrm{L}$ leucinol was also added to the mixture. ${ }^{[9]}$ On the other hand autocatalysis by the product has been observed before, e.g., in the related Mannich reaction: M. Mauksch, S. B. Tsogoeva, I. M. Martynova, S. Wei, Angew. Chem. Int. Ed. 2007, 46, 393-396; Angew. Chem. 2007, 119, 397-400.

[21] Gaussian 09, Revision C.01, 2010 (full ref is given in $\mathrm{SI}$ ).

[22] (a) A. D. Becke Phys. Rev. A 1998, 38, 3098-3100; (b) C. Lee, W. Yang, R. G. Parr, Phys. Rev. B 1988, 37, 785-789; (c) B. Miehlich, A. Savin, H. Stoll, H. Preuss, Chem. Phys. Lett. 1989, 157, 200-206; (d) V. Barone, M. Cossi, J. Phys. Chem. A 1998, 102, 1995-2001; (e) M Cossi, N. Rega, G. Scalmani, V. Barone, J. Comp. Chem. 2003, 24, 669-681; (f) J. M. Tao, J. P. Perdew, V. N. Staroverov, G. E. Scuseria Phys. Rev. Lett. 2003, 91, 146401; (g) J.-D. Chai, M. Head-Gordon, Phys. Chem. Chem. Phys. 2008, 10, 6615-6620; (h) R. A. Kendall, T. H. Dunning, R. J. Harrison, J. Chem. Phys. 1992, 96, 6796-6806.

[23] (a) TURBOMOLE V6.4 2012, a development of University of Karlsruhe and Forschungszentrum Karlsruhe $\mathrm{GmbH}, 1989-2007$, TURBOMOLE $\mathrm{GmbH}$, since 2007; available from www.turbomole.com. (b) J. A. Pople M. Head-Gordon and K. Raghavachari, J. Chem. Phys. 1987, 87, 5968 5975. (c) F. Weigend, M. Häser, H. Patzelt, R. Ahlrichs, Chem. Phys. Lett. 1998, 294, 143-152; (d) A. Klamt, V. Jonas, T. Bürger, J. C Lohrenz, J. Phys. Chem. A 1998, 102, 5074-5085. (e) S. Schenker, C. Schneider, S. B. Tsogoeva, T. Clark, J. Chem. Theory Comp. 2011, 7 3586-3595.

[24] A. V. Marenich, C. J. Cramer, D. G. Truhlar, J. Phys. Chem. B 2009 113, 6378-6396.

[25] For a discussion of the syn/anti-enamines and detailed investigation of the aldol reaction, see refs $\left[14^{\mathrm{d}}, 17,19\right]$.

[26] These differences, i.e., $0.4 \mathrm{kcal} \mathrm{mol}^{-1}$ in each instance, are rather marginal. Therefore, one has to be rather careful to make definite conclusions. 
[27] (a) E. V. Anslyn, D. A. Dougherty, Modern Physical Organic Chemistry University Science Books, 2006, p 378. See also: (b) J. I. Seeman, J. Chem. Ed. 1986, 63, 42-48.

[28] For the aldol reaction of isatin with acetone, mediated by non-chira secondary amines or $\mathrm{K}_{2} \mathrm{CO}_{3}$, see: (a) F. Braude, H. G. Lindwall, J. Am. Chem. Soc. 1933, 55, 325-327; (b) S. J. Garden, J. C. Torres, A. A Ferreira, R. B. da Silva, A. C. Pinto, Tetrahedron Lett. 1997, 38, 15011504; (c) S. J. Garden, R. B. da Silva, A. C. Pinto, Tetrahedron 2002 $58,8399-8412$

[29] For a recent detailed review and discussion of kinetic isotope effects, see: (a) M. Gómez-Galleo, M. A. Sierra, Chem. Rev. 2011, 111, 4857 4963; (b) E. M. Simmons, J. F. Hartwig, Angew. Chem. Int. Ed. 2012 51, 3066-3072.

[30] The KIE can, in principle, also originate from the formation of the corresponding enolate or enol (rather than enamine). However, the enolate itself could hardly be expected to react with $>90 \%$ enantioselectivity, even if a loose coordination to the chiral catalyst as simple as leucinol were considered. On the other hand, this mechanism may contribute to the low enantioselectivity observed in the early stages of the reaction. ${ }^{[9]}$ Apparently, the enolate mechanism can only be effective with multifunctional catalysts, such as chiral thioureas. ${ }^{[10 b, c]}$
[31] In a reciprocal experiment, i.e., in the L-leucinol-catalyzed reaction of isatin (1a) with non-labeled acetone, carried out in the presence of $\mathrm{D}_{2} \mathrm{O}$ (1 equiv), a KIE $\left(k_{\mathrm{H}} / k_{\mathrm{D}}=1.5\right)$ was also observed. This effect can be attributed to an $\mathrm{H} / \mathrm{D}$ exchange of the $\mathrm{N}-\mathrm{H}$ of isatin (note that hydrogen bonding involving the $\mathrm{N}-\mathrm{H}$ is featured in the $\mathrm{TS}^{\neq}$10/11 as shown in Scheme 3).

[32] Another example of the rate limiting step preceding the $\mathrm{C}-\mathrm{C}$ bond formation in the aldol reaction can be drawn from the aldol reaction in the Hajos-Parish experiment (catalyzed by proline), where the enamine formation is an intermolecular process, whereas the subsequent aldol $\mathrm{C}-\mathrm{C}$ bond formation is intramolecular (and therefore entropically favorable): H. Zhu, F. R. Clemente, K. N. Houk, M. P. Meyer, J. Am. Chem. Soc. 2009, 131, 1632-1633.

[33] Both experimental and computational results show that this aldo reaction is an example of the general base catalysis; for an excellent discussion, see: A. Ault, J. Chem. Ed. 2007, 84, 30-39.

[34] (a) R. G. Compton, Electron Tunneling in Chemistry. In Comprehensive Chemical Kinetics, Elsevier, New York; 1989; Vol. 30; (b) S. HammesSchiffer, Acc. Chem. Res. 2006, 39, 93-100. 
Layout 2:

\section{FULL PAPER}

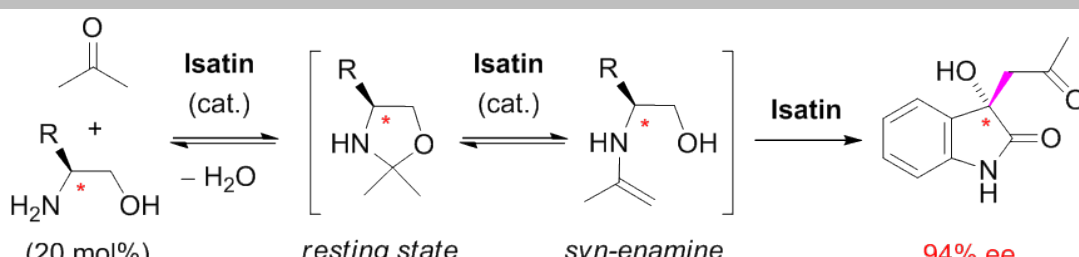

Self-catalysis in organocatalysis. Comprehensive mechanistic studies of the enantioselective aldol reaction between isatin and acetone, catalysed by L-leucinol, unraveled that isatine, apart from being a substrate, also plays an active catalytic role.

Mikhail A. Kabeshov, * Ondřej Kysilka, Lubomír Rulíšek, Yury V. Suleimanov, Marco Bella, Andrei V. Malkov, ${ }^{*}$ and Pavel Kočovský*

Page No. - Page No.

Cross-Aldol Reaction of Isatin with Acetone Catalyzed by Leucinol: A Mechanistic Investigation 